\title{
Comparison of autograft versus allograft in the surgical repair of pediatric obstetrical brachial plexus injuries
}

\author{
Laura G. Hamant, MD, ${ }^{1}$ P. David Adelson, MD, ${ }^{1-4}$ Paul Kang, MS, MPH, ${ }^{4}$ \\ S. Danielle Brown, RN, MSN, ${ }^{2}$ and Jorge I. Arango, MD² \\ 1Phoenix Children's Hospital and 2Barrow Neurological Institute at Phoenix Children's Hospital, Phoenix, Arizona; ${ }^{3}$ Mayo Clinic \\ School of Medicine, Rochester, Minnesota; and ${ }^{4}$ University of Arizona, College of Medicine-Phoenix, Arizona
}

\begin{abstract}
OBJECTIVE The goal of this study was to determine the functional efficacy of acellular processed nerve allograft (ALG) as compared to sural nerve autograft (AUG) harvested at time of surgery for children with obstetrical brachial plexus injury (OBPI).

METHODS A retrospective review of records was performed in patients who underwent surgical repair of OBPI between 2009 and 2015 at Phoenix Children's Hospital. Patients were grouped based on the type of nerve graft used (AUG using the patient's own sural nerve or decellularized processed cadaveric nerve ALG) and compared in terms of motor strength, British Medical Research Council score, functionality (Mallet scale score), surgical time, rate of complications, and need for further intervention.
\end{abstract}

RESULTS A total of 52 records were identified meeting study criteria. Sural nerve AUG was used in 22 cases and ALG in 30 cases. Changes from pre- to postsurgical assessment of motor strength were significant for all muscle groups measured except for elbow extension for both groups. All Mallet scores increased significantly. No significant differences were observed in motor strength and functional components between groups. Interventions using ALG had shorter operative times than those performed using AUG. No significant difference was observed in terms of need for further intervention. Two patients (9\%) in the AUG group developed stitch abscesses at the harvest site, whereas there were no infectious complications reported in the ALG group.

CONCLUSIONS These findings suggest equivalence in terms of muscle strength and functional outcomes between the use of AUG and ALG for patients with OBPI. However, the less invasive character of ALG repair decreases surgical time and risk of complications.

https://thejns.org/doi/abs/10.3171/2020.4.PEDS2033

KEYWORDS pediatric; obstetrical; brachial plexus; injury; peripheral nerve

$\mathrm{O}$ BSTETRICAL brachial plexus injuries (OBPIs) occur during delivery, with a global incidence ranging from $0.2 \%$ to $4 \%$ of live births. ${ }^{1,2}$ Factors associated with OBPI include high birth weight (> $4000 \mathrm{~g})$, prolonged labor course, breech delivery, and shoulder dystocia. ${ }^{2}$ Damage to the brachial plexus (BP) can result in a wide range of dysfunction depending on the extent and severity of the injury. A favorable prognosis is expected in up to $95 \%$ of patients and is associated with early clinical improvement, normal or near-normal strength in multiple muscle groups, and/or good functional recovery. ${ }^{3,4}$ However, when patients fail to recover their functionality, surgical repair is often recommended. Poor prognostic indi- cators include Horner syndrome, no neurological recovery by 4-6 months, and flail upper limb., ${ }^{1,5-8}$ Absence of elbow flexion at 3-4 months of age has historically been used as an early predictor for surgical management. ${ }^{4,6}$

The primary surgery for OBPI consists of intraoperative neurophysiological testing, external and internal neurolysis and/or excision of the neuroma, and nerve grafting. Nerve grafting can be performed using sural nerve autograft (AUG) or acellular deproteinized sural nerve allograft (ALG). AUG is harvested from the lower extremities of the patient, requiring a separate incision and carrying additional potential morbidity (i.e., numbness on the dorsum of the foot, increased risk of infection). Additionally, there

ABBREVIATIONS ALG = allograft; AUG = autograft; BMRC = British Medical Research Council; $B P=$ brachial plexus; OBPI = obstetrical brachial plexus injury. SUBMITTED January 27, 2020. ACCEPTED April 8, 2020.

INCLUDE WHEN CITING Published online June 12, 2020; DOI: 10.3171/2020.4.PEDS2033. 
can be variability in the amount of length (even with use of bilateral sural nerves), quality, and caliber of the sural nerve available in each patient. In contrast, ALG has the potential benefit of consistent diameter premeasured as well as unlimited length and number of grafts available. It can also provide a pathway for axonal outgrowth without sacrificing function or increasing the risk of infection.

We hypothesized that sural nerve AUG and ALG will have similar outcomes in motor strength and functional outcome following surgery and that using ALG will result in shorter operative times without an increase in complications or rate of future surgeries. The aim of this study was to compare the functional outcomes of BP repair with AUG and ALG for OBPI.

\section{Methods}

\section{Approval}

This study was approved by the Phoenix Children's Hospital Institutional Review Board through expedited review.

\section{Record Identification}

A retrospective chart review was performed in consecutive patients who underwent $\mathrm{BP}$ repair after OBPI with either an AUG or an ALG at Barrow Neurological Institute at Phoenix Children's Hospital between January 2009 and December 2015 by a single surgeon (P.D.A.). Patients admitted before August 2012 were treated consecutively with AUG, and afterward patients were treated using ALG; no other factors besides timing were considered. Patients were included in this study if 1) their injury was due to obstetrical birth trauma or injury; 2) there was some recovery (British Medical Research Council [BMRC] motor strength scale [a converted pediatric motor scale] $]^{3,9,26}$ score $\leq 3$ in muscles innervated by $\mathrm{C} 5-7$ ) and the patient was lacking functional recovery on examination (Mallet score < III on hand to mouth testing) of the ipsilateral upper extremity by at least 4-6 months postinjury; and 3) the child had plateaued in their functional recovery (i.e., no improvement in the interim 4- to 6-week clinic visit) and then subsequently underwent surgical repair including nerve grafting. Patients who suffered mechanisms of injury other than OBPI or other peripheral nerve injuries, avulsion-type injuries, or complete BP/flail arm injuries were excluded and no patient who made a functional recovery (Mallet score $\geq$ III) underwent surgical intervention. There were no imaging or electrophysiological studies obtained in this cohort of patients because there was some recovery of function in the muscle groups, indicating it was unlikely that these children suffered an avulsion-type injury. Given that these studies would not change decision-making for surgical intervention and electrophysiological studies are obtained intraoperatively, inclusion for this type of intervention depended on the neurological examination and trajectory of recovery.

\section{Surgical Approach}

The following surgical procedure was used for all of the patients included for review. ${ }^{1}$ In the AUG group, the ipsilateral sural nerve (and contralateral if necessary) was initially exposed through a vertical incision paralleling the nerve at the posterolateral aspect of the malleolus. Once the sural nerve was dissected free and identified distally, the incision was then extended either vertically along the tract of the sural nerve or through cross-hatch or stairsteptype incisions proximal to the level of the gastrocnemius to provide sufficient length of AUG. If necessary, graft was obtained bilaterally, although this occurred rarely. The nerve grafts were protected in a nonstick gauze and kept moist until needed. The incisions were closed with resorbable sutures.

For both groups, the BP was surgically approached through a linear incision parallel to and approximately one finger breadth above the clavicle, with dissection and exposure through the lateral triangle (Fig. 1). The platysma was incised in an "L" shape along the clavicle and then superiorly along the lateral edge of the sternocleidomastoid muscle. The muscle and underlying fat pad along with the omohyoid muscle were reflected posterosuperiorly. The anterior scalene was exposed and the phrenic nerve identified and protected to ensure against injury. The anterior scalene was then mobilized to provide sufficient exposure of each root of the BP (Fig. 2).

Electrophysiological studies were performed intraoperatively for each of the nerve roots of the BP (C5-8), including somatosensory evoked potentials and electromyography/nerve conduction studies to determine the function of the neuromuscular unit and connection to the spinal cord. If there was no conduction proximally indicating an avulsion, then grafting from that nerve root was avoided. If there was conduction across the damaged segment/neuroma, an external neurolysis and an internal neurolysis were performed to release restrictive scar tissue. The internal neurolysis was also used to identify matching fascicles proximally at the root level and distal at the division level, for later end-to-side "jump" grafting to bypass the neuroma from the proximal "normal" functioning nerve root to the distal intact, uninjured divisions. Although it was planned that if there was no conduction distally through the neuroma, then it would be resected and an end-to-end "cable" interpositional nerve graft would be fashioned, there were no patients during the study period who had a neuroma resected and interpositional grafts placed.

During the microscopic internal neurolysis of each of the proximal nerve roots, multiple fascicles were exposed and electrophysiologically stimulated to identify their distal targets (i.e., triceps, biceps, deltoid, and spinati). These were then matched distally to fascicles at the level of the divisions innervating similar muscle groups. For C7, proximal and distal fascicles in the posterior division to the triceps were targeted; for C6, stimulation of biceps fascicles were targeted to similar fascicles distally in the anterior division; and for C5, fascicles to the deltoid proximally (usually found in the ventral medial portion of the C5 root) were grafted to deltoid fascicles in the posterior division. Last, fascicles to the spinati proximally (usually found in the dorsal lateral portion of the C5 root) were targeted to the suprascapular nerve.

For "jump" grafting, early cases in the series used nerve graft obtained through an autologous sural nerve harvest. The AUGs were variable in size and condition, 
depending on each individual patient's anatomy. The later series of patients received ALG (Avance AxoGen Corp.), sterile processed cadaveric decellularized, deproteinized human nerves that maintain the structure of the extracellular matrix of the nerve to provide a 3D scaffold for axon regeneration and consistent diameter of $1-2 \mathrm{~mm} .{ }^{10}$ This nerve graft product is FDA approved for surgical repair to bridge nerve discontinuities and is considered human transplantation tissue in accordance with US FDA requirements for human cellular and tissue-based products under 21 CFR Part 1271 regulations, US state regulations, and the guidelines of the American Association of Tissue Banks. Each graft was cut to sufficient length to cover the distance from the proximal nerve root to the distal division beyond the neuroma without tension, usually 1.5- to $2.5-\mathrm{cm}$ lengths. Each graft was sutured with 2 epineurial stitches using 9-0 nylon both proximal and distal to maintain apposition of the grafts to the underlying fascicles. No tissue sealant (i.e., Tisseal) was used in any of the cases (Fig. 3).

Following closure with resorbable suture, the patients were immobilized in a sling for 2 weeks and then slowly advanced through a graduated therapy program; initially with daily gentle range of motion for 2 weeks, followed by regular therapy sessions beginning at 4 weeks postoperatively. All patients were prescribed physical and/or occupational therapy at least once a week, although families were instructed to do "therapy" at home with the child on a daily basis. Routine follow-up occurred in the Brachial Plexus and Peripheral Nerve Injury ambulatory clinic preand postoperatively at a minimum of 6 months following surgery. At each clinic visit, each child underwent a full neurological examination and functional assessment by the senior author/primary surgeon (P.D.A.) and an occupational therapist. Functionality (Mallet score) and motor strength of multiple independent muscles were both assessed before and after surgery. Data as to outcomes were solely based on the examination of the senior author. Independent variables that were collected to determine if there were any confounding factors included sex, side of injury, birth history, comorbidities, associated injuries, and type of surgical repair. All patients were evaluated and surgically managed by the primary surgeon, and all the outcome evaluations were provided by a single rater.

\section{Primary Outcomes}

For this study, the primary outcome measures were motor recovery using the BMRC motor strength scale (converted pediatric motor scale) ) $^{3,11,12,26}$ and functionality (Mallet score) ${ }^{9,11}$ through the patients' last recorded clinic visit.

\section{Secondary Outcome Measures}

Secondary outcome measures comparing the AUG and ALG groups included surgery duration as derived from the operative record, rate of complications based on the postoperative follow-up visits, and rate of future need of other surgeries. The common complications evaluated in the review included whether any patients had infection, worsened neurological examination results, painful scar at

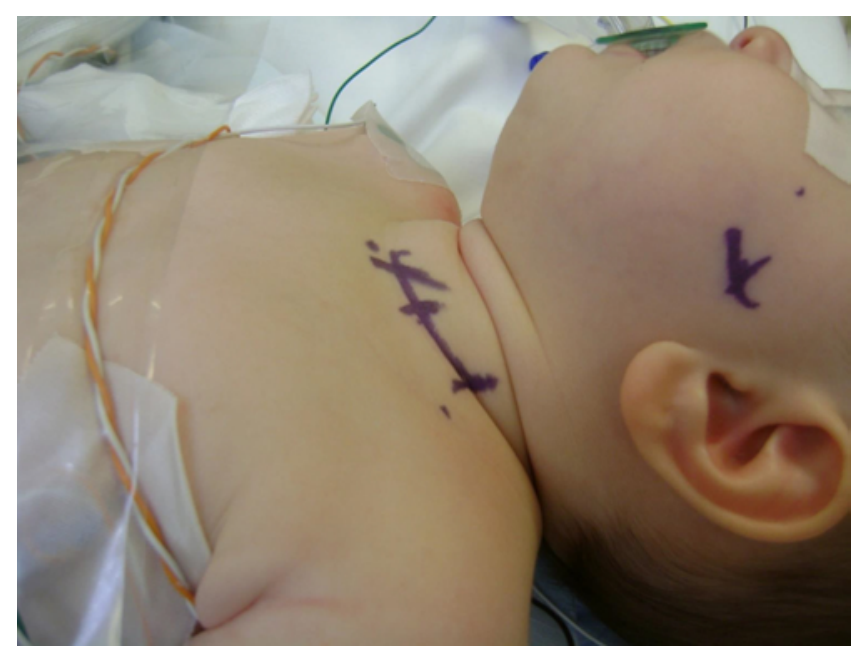

FIG. 1. Incision marked out over the left lateral triangle just superior to the clavicle. Figure is available in color online only.

the repair sites, and/or unexpected or planned return to the operating room.

\section{Statistical Analysis}

Demographic and clinical characteristics of patients who underwent the AUG and ALG interventions were evaluated using descriptive statistics including means (SDs) for continuous variables, and frequencies and proportions for categorical variables. The Wilcoxon rank-sum test was used to assess the difference in mean scores preand postoperatively between patients who underwent the AUG and ALG interventions. The Fisher exact test was used to compare proportions and complications between groups. Multiple linear regression was used to ascertain the estimated mean difference of the duration of surgery between the 2 types of surgeries (i.e., operations performed using ALG or AUG), with the AUG group as the reference group. Multiple logistic regression was used to ascertain the likelihood of subsequent surgeries between the ALG and AUG groups, using the AUG group as a reference group. All $\mathrm{p}$ values were 2 -sided and $\mathrm{p}<0.05$ was considered statistically significant. All data analyses were conducted using Stata version 14 (StataCorp.).

\section{Results}

In total, we identified 52 patients, $22(42.3 \%)$ in the AUG group and 30 (57.7\%) in the ALG group, all of whom underwent surgical intervention before 9 months of age. The only significant difference in demographics between the 2 groups was that the AUG group had a greater prevalence of patients with multiparous mothers (64\% vs 33\%). Otherwise, there were no statistically significant differences in demographic and clinical characteristics between the groups (Table 1). With respect to injury type, a noticeable difference in the prevalence of right limb injuries was observed between the 2 groups, with $73 \%$ of the AUG patients and $47 \%$ of the ALG patients experiencing rightsided BP injuries. However, this difference only showed trends toward significance $(\mathrm{p}=0.06)$ (Table 2$)$. There were 

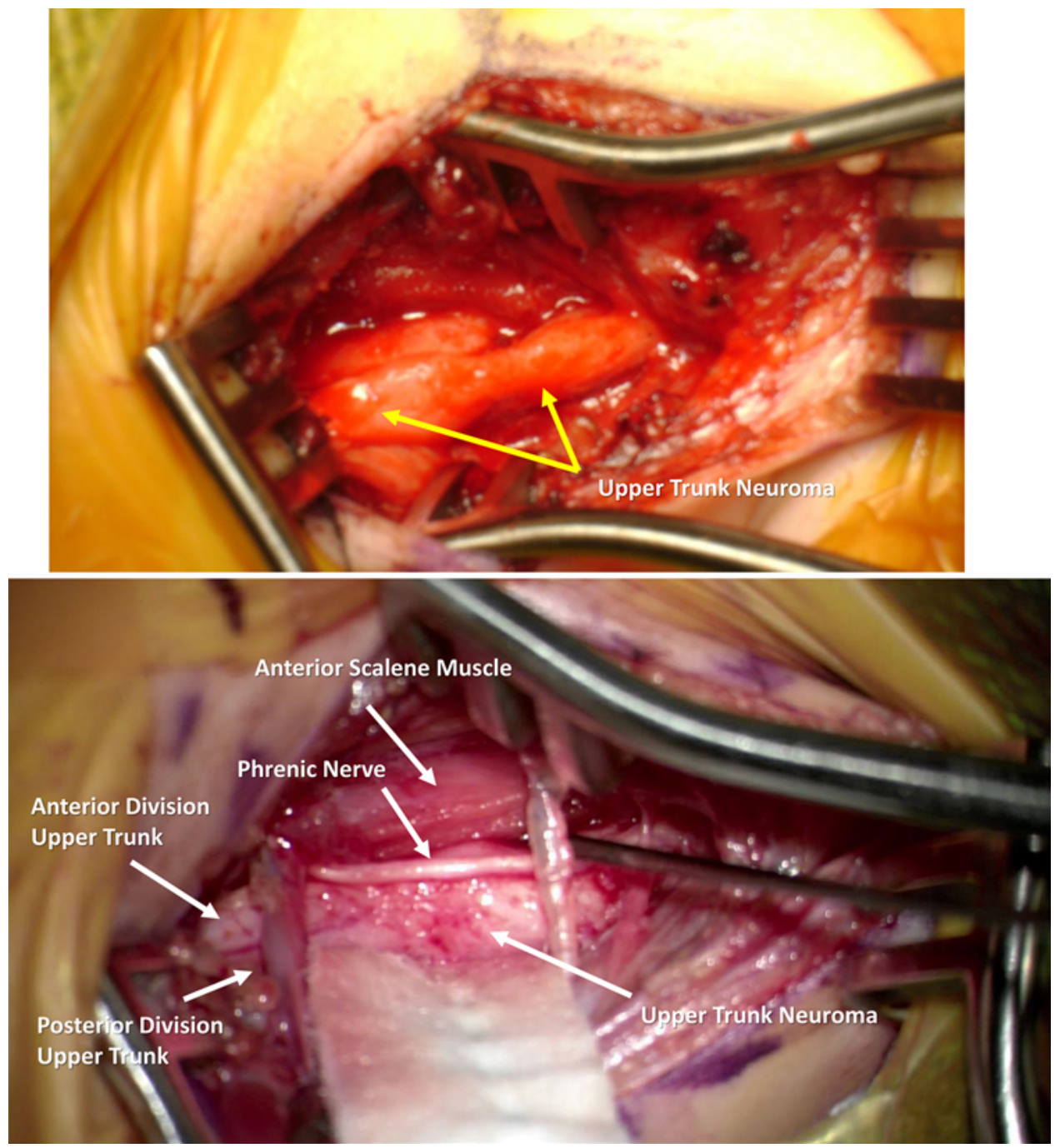

FIG. 2. Upper: Intraoperative view of the exposed anatomy including the upper trunk neuroma. Lower: Intraoperative view showing the exposed anatomy. Figure is available in color online only.

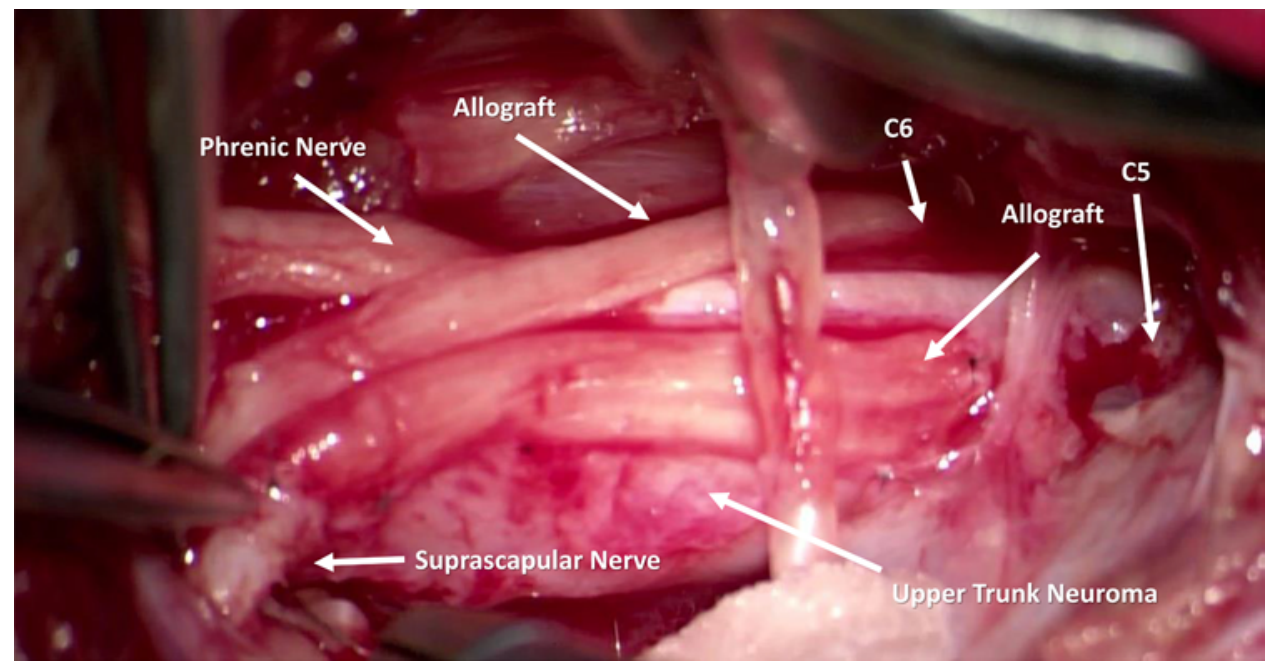

FIG. 3. Intraoperative view showing the ALGs from proximal nerve root to distal division. Figure is available in color online only. 
TABLE 1. Demographic data and clinical characteristics in 52 pediatric patients with $\mathrm{OBPI}$

\begin{tabular}{|c|c|c|c|}
\hline \multirow[b]{2}{*}{ Variables } & \multicolumn{2}{|c|}{ No. in Group (\%) } & \multirow[b]{2}{*}{$\begin{array}{c}p \\
\text { Value }\end{array}$} \\
\hline & $\begin{array}{l}\text { AUG, } \\
n=22\end{array}$ & $\begin{array}{c}\text { ALG, } \\
n=30\end{array}$ & \\
\hline Male sex & $8(36.4)$ & $17(56.7)$ & 0.15 \\
\hline \multicolumn{4}{|l|}{ Maternal medical history } \\
\hline Musculoskeletal disorders & $0(0.0)$ & $1(3.3)$ & 1.0 \\
\hline Gestational diabetes & $4(18.2)$ & $1(3.3)$ & 0.15 \\
\hline Hypertension & $5(22.7)$ & $3(10.0)$ & 0.26 \\
\hline Immunocompromised & $0(0.0)$ & $0(0.0)$ & NA \\
\hline Difficult healing & $0(0.0)$ & $1(3.3)$ & 1.0 \\
\hline Peripheral neuropathy & $0(0.0)$ & $0(0.0)$ & NA \\
\hline Excessive weight gain in pregnancy & $1(4.6)$ & $0(0.0)$ & 0.42 \\
\hline Other maternal history & $12(54.6)$ & $18(60.0)$ & 0.69 \\
\hline Mother's occupation, office admin & $7(31.8)$ & $13(43.3)$ & 0.24 \\
\hline Smoking history, nonsmoker & $14(63.6)$ & $19(63.3)$ & 0.98 \\
\hline Mother's gravida no. & & & 0.20 \\
\hline 1 & $8(36.4)$ & $12(40.0)$ & \\
\hline 2 & $2(9.1)$ & $8(26.7)$ & \\
\hline$\geq 3$ & $12(54.6)$ & $10(33.3)$ & \\
\hline$>1$ live children delivered & $14(63.6)$ & $10(33.3)$ & 0.03 \\
\hline \multicolumn{4}{|l|}{ Child's medical history } \\
\hline Delivery by C-section & $3(13.6)$ & $1(3.3)$ & 0.30 \\
\hline Shoulder dystocia & $17(77.3)$ & $17(56.7)$ & 0.15 \\
\hline Vacuum & 4 (18.2) & $4(13.3)$ & 0.70 \\
\hline Forceps & $3(13.6)$ & $4(13.3)$ & 1.0 \\
\hline Needed NICU & $4(18.2)$ & $2(6.7)$ & 0.38 \\
\hline Sibling with OBPI & $0(0.0)$ & $0(0.0)$ & NA \\
\hline Neurological disorder & $2(9.1)$ & $1(3.3)$ & 0.56 \\
\hline Peripheral neuropathy & $0(0.0)$ & $0(0.0)$ & NA \\
\hline Musculoskeletal disorder & $0(0.0)$ & $2(6.7)$ & 0.50 \\
\hline Diabetes & $0(0.0)$ & $0(0.0)$ & NA \\
\hline Hypertension & $0(0.0)$ & $0(0.0)$ & NA \\
\hline Immunocompromised & $0(0.0)$ & $0(0.0)$ & NA \\
\hline Difficulty healing & $0(0.0)$ & $0(0.0)$ & NA \\
\hline
\end{tabular}

Admin = administrator; C-section = cesarean section; NA = not applicable; $\mathrm{NICU}=$ neonatal intensive care.

Chi-square/Fisher's exact test used to compare categorical variables.

otherwise no differences between the 2 groups as to age at surgery, sex, or any other demographic or clinical characteristic. The mean time from surgery through last followup was 614 (547) days (range 180-2099 days) or 1.7 (1.5) years (range $0.5-5.75$ years).

In the combined cohort of children who underwent the primary surgery for neuroplasty and nerve grafting, whether they received AUG or ALG, there were significant improvements comparing preoperative to the postoperative motor assessments for each muscle group measured $(p<0.05)$, except for elbow extension (Table 3). Similarly, with regard to functionality, each component of the Mallet score showed statistically significant increases, with the largest increases in the mean global abduction scores
TABLE 2. Characteristics of nerve injury in 52 pediatric patients with OBPI

\begin{tabular}{lccc}
\hline \multirow{2}{*}{ Variables } & \multicolumn{2}{c}{ No. in Group (\%) } & \\
\cline { 2 - 3 } & AUG, $\mathrm{n}=22$ & ALG, $\mathrm{n}=30$ & p Value \\
\hline Mechanism of injury, OBPI & $21(95.5)$ & $29(96.7)$ & 1.0 \\
\hline Affected limb, rt side & $16(72.7)$ & $14(46.7)$ & 0.06 \\
\hline C5, postganglionic & $19(86.4)$ & $23(76.7)$ & 0.48 \\
\hline C6, postganglionic & $19(86.4)$ & $24(80.0)$ & 0.71 \\
\hline C7, postganglionic & $15(68.2)$ & $21(70.0)$ & 0.88 \\
\hline C8, postganglionic & $3(13.6)$ & $4(13.3)$ & 1.0 \\
\hline T1, postganglionic & $2(9.1)$ & $3(10.0)$ & 1.0 \\
\hline Fracture to clavicle & $0(0.0)$ & $3(10.0)$ & 0.25 \\
\hline Fracture to humerus & $0(0.0)$ & $1(3.3)$ & 1.0 \\
\hline Phrenic nerve injury & $0(0.0)$ & $0(0.0)$ & NA \\
\hline Anoxic brain injury & $0(0.0)$ & $1(3.3)$ & 1.0 \\
\hline Horner's syndrome & $2(9.1)$ & $2(6.7)$ & 1.0 \\
\hline
\end{tabular}

Chi-square/Fisher's exact test used to compare categorical variables.

(preoperative score 2.23 [0.89] vs postoperative score 3.46 [1.05]; $\mathrm{p}<0.001$ ) and the hand to mouth scores (preoperative score 1.88 [0.71] vs postoperative scores 3.09 [1.06]; $\mathrm{p}<0.001)$.

When each of the study groups was analyzed separately, again there were significant improvements in both

TABLE 3. Mean pre- and postoperative scores for groups combined

\begin{tabular}{lccc}
\hline & \multicolumn{2}{c}{ Mean (SD) } & \\
\cline { 2 - 3 } \multicolumn{1}{c}{ Variables } & Preop & Postop & p Value \\
\hline BMRC motor score & & & \\
\hline Shoulder flexion & $2.07(1.24)$ & $3.36(1.09)$ & $<0.001$ \\
\hline Shoulder abduction & $2.80(3.49)$ & $3.61(1.16)$ & $<0.001$ \\
\hline Shoulder external rotation & $0.77(0.92)$ & $2.48(1.50)$ & $<0.001$ \\
\hline Elbow flexion & $2.22(1.29)$ & $3.61(1.12)$ & $<0.001$ \\
\hline Elbow extension & $3.45(1.35)$ & $3.70(1.26)$ & 0.23 \\
\hline Forearm pronation & $3.37(1.23)$ & $4.09(0.81)$ & $<0.001$ \\
\hline Forearm supination & $1.22(1.09)$ & $2.57(1.44)$ & $<0.001$ \\
\hline Wrist flexion & $3.26(1.63)$ & $4.08(1.31)$ & $<0.001$ \\
\hline Wrist extension & $2.78(1.70)$ & $3.67(1.51)$ & $<0.001$ \\
\hline Digit flexion & $3.67(1.58)$ & $4.15(1.00)$ & 0.005 \\
\hline Digit extension & $3.27(1.55)$ & $4.00(1.19)$ & $<0.001$ \\
\hline Mallet score & & & \\
\hline Arm at rest & $2.20(0.90)$ & $3.02(0.98)$ & $<0.001$ \\
\hline Global abduction & $2.23(0.89)$ & $3.46(1.05)$ & $<0.001$ \\
\hline Global external rotation & $2.11(0.79)$ & $3.00(0.84)$ & $<0.001$ \\
\hline Head and neck & $1.81(0.62)$ & $2.81(1.29)$ & $<0.001$ \\
\hline Head and spine & $1.93(0.66)$ & $2.90(0.89)$ & $<0.001$ \\
\hline Head to mouth & $1.88(0.71)$ & $3.09(1.06)$ & $<0.001$ \\
\hline Supination & $1.93(0.75)$ & $2.92(0.84)$ & $<0.001$ \\
\hline
\end{tabular}

Wilcoxon signed-rank test used to compare pre- to postoperative outcomes. 
TABLE 4. Change in mean scores between groups

\begin{tabular}{lccc}
\hline \multirow{2}{*}{ Variables } & \multicolumn{2}{c}{$\Delta$ Mean (SD) } & p \\
\cline { 2 - 3 } & AUG, $\mathrm{n}=22$ & ALG, $\mathrm{n}=30$ & Value \\
\hline BMRC motor score & & & \\
\hline Shoulder flexion & $1.17(0.41)$ & $1.46(1.12)$ & 0.83 \\
\hline Shoulder abduction & $1.42(0.79)$ & $0.58(4.52)$ & 0.97 \\
\hline Shoulder external rotation & $1.87(1.35)$ & $2.11(1.49)$ & 0.64 \\
\hline Elbow flexion & $1.43(1.34)$ & $1.40(1.24)$ & 0.51 \\
\hline Elbow extension & $-0.14(1.23)$ & $0.41(1.08)$ & 0.22 \\
\hline Forearm pronation & $0.50(0.55)$ & $0.95(1.19)$ & 0.55 \\
\hline Forearm supination & $1.45(1.21)$ & $1.40(1.31)$ & 0.89 \\
\hline Wrist flexion & $1.13(1.64)$ & $0.73(1.16)$ & 0.49 \\
\hline Wrist extension & $0.13(1.72)$ & $1.19(1.46)$ & 0.35 \\
\hline Digit flexion & $0.23(1.01)$ & $0.67(1.20)$ & 0.50 \\
\hline Digit extension & $0.40(0.69)$ & $1.04(1.25)$ & 0.17 \\
\hline Mallet score & & & \\
\hline Arm at rest & $0.71(0.72)$ & $0.78(0.95)$ & 0.79 \\
\hline Global abduction & $1.07(1.11)$ & $1.25(0.75)$ & 0.66 \\
\hline Global external rotation & $1.00(0.78)$ & $0.78(0.75)$ & 0.37 \\
\hline Head and neck & $1.07(1.03)$ & $0.93(1.29)$ & 0.56 \\
\hline Head and spine & $1.00(0.84)$ & $1.00(0.87)$ & 0.94 \\
\hline Head to mouth & $1.31(0.94)$ & $1.11(1.18)$ & 0.54 \\
\hline Supination & $0.71(0.82)$ & $1.11(0.99)$ & 0.23 \\
\hline Wilcoxon rank-sum & &
\end{tabular}

Wilcoxon rank-sum test used to compare continuous variables.

motor and functional scores (Table 4) in every component score except for elbow extension in the AUG group. As well, the change in mean scores from preoperative assessment to final clinic visit showed no statistically significant difference between the AUG and ALG groups ( $p>0.05)$, indicating that neither one was superior in this study.

For the secondary outcome measures, the length of surgery time was decreased by 30.7 minutes (beta coefficient $-30.7 ; 95 \%$ CI $-62.7,1.31 ; p=0.06)$ in the ALG group as compared to AUG (Table 5). There were no complications reported for the ALG group, although there were 2 patients in the AUG group who had superficial infections with stitch abscesses in the incisions for the sural nerve harvest. There were no infections in the primary supraclavicular surgical site in either group. The complication rate was therefore not significantly different for AUG $(9 \%)$ as compared to those patients who received ALG $(0 \%$, $\mathrm{p}=0.17)$. Some patients did require additional surgeries to further improve function, and these included further neuroplasty, tendon and/or muscle transfers, tendon and/ or muscle releases ("Mod Quad"), humeral osteotomies, and musculotendinous lengthening, although these occurred 12-36 months following the primary surgery when the recovery from the primary surgery had plateaued. The rate of subsequent surgeries was not statistically different between groups, although patients in the ALG group were 2.69 times more likely to have a subsequent surgery (such as a tendon transfer or muscle release). However this was not statistically significant, with a large confidence interval (OR 2.69; 95\% CI 0.30, 23.9; $\mathrm{p}=0.37$ ) (Table 6).
TABLE 5. Association between group and length of surgery

\begin{tabular}{|c|c|c|}
\hline Variables & Beta $(95 \% \mathrm{Cl})$ & $\mathrm{p}$ Value \\
\hline \multicolumn{3}{|l|}{ Graft } \\
\hline AUG & Ref & \\
\hline ALG & $-30.7(-62.7,1.31)$ & 0.06 \\
\hline \multicolumn{3}{|l|}{ Sex } \\
\hline Female & Ref & \\
\hline Male & $-1.85(-35.2,31.5)$ & 0.91 \\
\hline \multicolumn{3}{|c|}{ Maternal musculoskeletal disorder } \\
\hline No & Ref & \\
\hline Yes & $76.84(-18.0,171.7)$ & 0.11 \\
\hline \multicolumn{3}{|l|}{ Maternal diabetes } \\
\hline No & Ref & \\
\hline Yes & $-57.7(-122.5,7.14)$ & 0.07 \\
\hline \multicolumn{3}{|l|}{ Maternal hypertension } \\
\hline No & Ref & \\
\hline Yes & $-24.1(-66.6,18.5)$ & 0.25 \\
\hline \multicolumn{3}{|l|}{ No. of children } \\
\hline$\leq 1$ & Ref & \\
\hline$>1$ & $-27.1(-60.4,4.44)$ & 0.08 \\
\hline \multicolumn{3}{|l|}{ Delivery } \\
\hline Vaginal & Ref & \\
\hline C-section & $-2.34(-56.6,51.9)$ & 0.93 \\
\hline \multicolumn{3}{|l|}{ NICU stay } \\
\hline No & Ref & \\
\hline Yes & $11.6(-37.9,61.1)$ & 0.63 \\
\hline \multicolumn{3}{|c|}{ Patient neurological disorder } \\
\hline No & Ref & \\
\hline Yes & $82.3(6.82,157.8)$ & 0.03 \\
\hline \multicolumn{3}{|l|}{ Affected limb } \\
\hline Lt & Ref & \\
\hline Rt & $-1.47(-29.8,26.8)$ & 0.81 \\
\hline \multicolumn{3}{|l|}{ C5 injury } \\
\hline No & Ref & \\
\hline Yes & $-13.8(-57.8,30.2)$ & 0.52 \\
\hline \multicolumn{3}{|l|}{ C6 injury } \\
\hline No & Ref & \\
\hline Yes & $-23.0(-68.9,22.9)$ & 0.31 \\
\hline \multicolumn{3}{|l|}{ Clavicle fracture } \\
\hline No & Ref & \\
\hline Yes & $49.1(-8.10,106.2)$ & 0.09 \\
\hline
\end{tabular}

Beta $(95 \% \mathrm{Cl})$ calculated using multiple linear regression adjusting for all other variables in the model.

\section{Discussion}

The decision-making for surgical intervention in children following an OBPI varies. ${ }^{4,8,13-15}$ Poor prognostic indicators for spontaneous recovery include Horner syndrome, no neurological recovery by 4 months, and flail upper limb. ${ }^{5,6,14}$ Some children recover various functions, but it is the extent of recovery that guides the decision-making for surgical intervention. Surgical treatment is generally 
TABLE 6. Association between graft and subsequent surgery

\begin{tabular}{|c|c|c|}
\hline Variables & OR $(95 \% \mathrm{Cl})$ & $\mathrm{p}$ Value \\
\hline \multicolumn{3}{|l|}{ Graft } \\
\hline AUG & Ref & \\
\hline ALG & $2.69(0.30,23.9)$ & 0.37 \\
\hline \multicolumn{3}{|l|}{ Sex } \\
\hline Female & Ref & \\
\hline Male & $0.27(0.04,2.01)$ & 0.21 \\
\hline \multicolumn{3}{|c|}{ Maternal diabetes } \\
\hline No & Ref & \\
\hline Yes & $0.11(0.002,6.01)$ & 0.28 \\
\hline \multicolumn{3}{|c|}{ Maternal occupation } \\
\hline Other & Ref & \\
\hline Office admin & $4.16(1.10,15.6)$ & 0.04 \\
\hline \multicolumn{3}{|l|}{ No. of children } \\
\hline$\leq 1$ & Ref & \\
\hline$>1$ & $0.19(0.02,2.05)$ & 0.17 \\
\hline \multicolumn{3}{|l|}{ Delivery } \\
\hline Vaginal & Ref & \\
\hline C-section & $0.20(0.0001,246.7)$ & 0.66 \\
\hline \multicolumn{3}{|l|}{ NICU stay } \\
\hline No & Ref & \\
\hline Yes & $13.8(0.53,359.1)$ & 0.11 \\
\hline \multicolumn{3}{|l|}{ Affected limb } \\
\hline $\mathrm{Lt}$ & Ref & \\
\hline $\mathrm{Rt}$ & $4.92(0.79,31.4)$ & 0.08 \\
\hline \multicolumn{3}{|l|}{ C5 injury } \\
\hline No & Ref & \\
\hline Yes & $0.07(0.006,0.93)$ & 0.04 \\
\hline \multicolumn{3}{|l|}{ Clavicle fracture } \\
\hline No & Ref & \\
\hline Yes & $12.0(0.56,256.7)$ & 0.11 \\
\hline
\end{tabular}

OR $(95 \% \mathrm{Cl})$ calculated using multiple logistic regression adjusting for all other variables in the model.

recommended for those patients who have not recovered functionality (i.e., ability to get the hand to the mouth against gravity by 4-6 months). ${ }^{4-6,16}$ Our indications for surgery have followed these recommendations although our surgical technique never included resection of the neuroma and interpositional grafts. Instead, our technique focused on neurophysiologically guided neuroplasty and matched fascicular nerve grafting from proximal to distal of the neuroma.

In our study the use of AUG and ALG for the treatment of OBPI during the primary surgery to repair the BP were found to be equally efficacious with regard to motor and functional outcomes as measured by the BMRC motor strength score and Mallet score, respectively. Importantly, all of the children who underwent surgical intervention using these grafting materials were found to improve, and most were able to gain functionality (i.e., ability to get their hand to their mouth to feed themselves-Mallet III). The surgical time was shorter in the use of ALG, although this only showed a trend toward significance and there were no differences in the rate of complications. Although the ALG group was more likely to have subsequent surgeries, this was not significant and was more due to an evolution in the development of the program than to any differences in the results from the primary surgery between the 2 groups as a possible factor in improving long-term functionality.

Peripheral nerve ALG safety and functionality in animal models has been well established. ${ }^{17}$ However, there is still controversy about the efficacy of ALG in comparison to AUG in animal models. In 1 study there was a significant decrease in nerve fibers and muscle mass in the acellular nerve ALG group. ${ }^{14}$ In another study there was no difference between AUG and ALG groups in terms of electrophysiological or histomorphological outcomes. ${ }^{13}$

In humans, limited studies have been done to determine efficacy differences between AUG and ALG. In an adult population, it has been shown that AUG and ALG sensory outcomes were similar in digital nerve reconstruction. ${ }^{18}$ Few studies have attempted to determine the efficacy of decellularized cadaveric nerve ALG for return of strength and functionality in humans. In comparing historical AUG data to peripheral nerve reconstruction using processed nerve ALG in an adult population, studies suggest that motor efficacy is similar. ${ }^{19,20}$ Through an extensive literature search, we have not found any studies that compared ALG to AUG in a pediatric population.

Reports and case series show mixed efficacy of ALG, especially over long segments. Presently, there is no current consensus on the optimal use of AUG as compared to ALG, although generally for long segments $(>5 \mathrm{~cm})$ AUG may be better ${ }^{21-23}$ In our study the graft segments tended to be short $(<2.5 \mathrm{~cm})$ due to the size of this patient population. As a result, the equal efficacy between the groups may be tied to the short segments and/or to the methodology for their use, and aligns with the present consensus - although this would need further study to better understand the electrophysiological and histomorphological outcomes in this patient population.

The safety of acellular nerve ALG in humans has also been well established. ${ }^{19,20,22,23}$ In these studies, there was no increase in infections, painful neuromas, rejection of foreign bodies, or any other complication related to their use. There have been no studies to date, though, showing the safety of the use of ALG in the pediatric population. Because there was no increase in complications or increased need for future surgery, this would seem to indicate that the use of ALG for the surgical treatment of OBPI in children is safe and would seem to parallel the findings in adults. In contrast, increased surgical time has been correlated to increased anesthesia, increased blood loss, and increased length of stay (and consequently increased costs incurred for the patient and the hospital). ${ }^{24,25}$ In our study, operative time was reduced by more than 30 minutes through the use of ALG as compared to the extra harvest time for AUG and would seem to add further justification for ALG use in these patients, although this savings may be partially offset by the cost and storage of the ALG.

\section{Limitations of the Study}

There are a number of limitations in this study. Because 
this is a retrospective sequential series of nonrandomized children, it is possible that there are unknown factors between the 2 groups, including surgical bias, timing of referral, availability of an upper-extremity surgeon to perform secondary procedures, etc. It was a small sample size as well. By limiting the cohort to one patient population, children undergoing primary repair of OBPI, this limited the sample size to one mechanism of injury in one hospital, creating a homogeneous study group that might not be generalizable to other children. Additionally, given that the surgeries and outcome assessments were performed by a single surgeon and the data were collected from the electronic medical record, the study was not blinded to the surgery and type of graft each patient received. Last, this study was powered to detect a significant difference of 0.8 between the pre- and postoperative motor and functional outcome scores. Because the change in the mean Mallet score was relatively small, between 0.71 and 1.31 for the AUG group and 0.75 and 1.25 for the ALG group (Table 4), we were not able to detect small differences between groups.

\section{Conclusions}

Overall, children who underwent surgical intervention for lack of functional recovery following OBPI had improved muscle strength and gained functionality postoperatively. Our analysis showed that nerve grafts using AUG and ALG were equally efficacious in motor and functional recovery for these children without an increase in complications. With two equally efficacious methods available, a less invasive method would seem to be preferable. For these reasons, our study would seem to indicate that the use of acellular ALG is an acceptable alternative to AUG in the surgical treatment of children with OBPI.

\section{Acknowledgments}

AxoGen provided funding support for data collection to a clinical registry.

\section{References}

1. Adelson PD. Brachial plexus injuries in childhood. In: Albright L, Pollack IF, Adelson PD, eds. Principles and Practice of Pediatric Neurosurgery. 2nd ed. Georg Thieme Verlag; 2007:884-907.

2. Doumouchtsis SK, Arulkumaran S. Are all brachial plexus injuries caused by shoulder dystocia? Obstet Gynecol Surv. 2009;64(9):615-623.

3. Gianinazzi ME, Rueegg CS, Zimmerman K, et al. Intra-rater and inter-rater reliability of a medical record abstraction study on transition of care after childhood cancer. PLoS One. 2015;10(5):e0124290.

4. Tassin JL. Paralysies Obstetricales du Plexus Brachial: Evolution Spontanee, Resultats des Interventions Reparatrices Precoces. Master's thesis. Université Paris VII; 1983.

5. Bade SA, Lin JC, Curtis CG, Clarke HM. Extending the indications for primary nerve surgery in obstetrical brachial plexus palsy. BioMed Res Int. 2014;2014:627067.

6. Hentz VR, Meyer RD: Brachial plexus microsurgery in children. Microsurgery 1991;12:175-185.

7. Mencl L, Waldauf P, Haninec P. Results of nerve reconstructions in treatment of obstetrical brachial plexus injuries. Acta Neurochir (Wien). 2015;157(4):673-680.
8. Waters PM, Bae DS. Brachial plexus birth palsy: rationale for a multicenter prospective study. Semin Plast Surg. 2004;18(4):377-384.

9. Mallet J. Obstetrical paralysis of the brachial plexus. II. Therapeutics. Treatment of sequelae. Priority for the treatment of the shoulder. Method for the expression of results. Article in French. Rev Chir Orthop Repar Appar Mot. 1972;58(suppl 1):166-168.

10. AxoGen: Science of nerve repair. Avance nerve graft. Accessed April 23, 2020. https://www.axogeninc.com/avancenerve-graft/

11. Bae DS, Waters PM, Zurakowski D: Reliability of three classification systems measuring active motion in brachial plexus birth palsy. J Bone Joint Surg Am. 2003;85(9):1733-1738.

12. Paternostro-Sluga T, Grim-Stieger M, Posch M, et al. Reliability and validity of the Medical Research Council (MRC) scale and a modified scale for testing muscle strength in patients with radial palsy. J Rehabil Med. 2008;40(8):665-671.

13. Tang P, Kilic A, Konopka G, et al. Histologic and functional outcomes of nerve defects treated with acellular allograft versus cabled autograft in a rat model. Microsurgery. 2013;33(6):460-467.

14. Wakimura Y, Wang W, Itoh S, et al. An experimental study to bridge a nerve gap with a decellularized allogeneic nerve. Plast Reconstr Surg. 2015;136(3):319e-327e.

15. Waters PM. Update on management of pediatric brachial plexus palsy. J Pediatr Orthop. 2005;25(1):116-126.

16. Clarke HM, Curtis CG. An approach to obstetrical brachial plexus injuries. Hand Clin. 1995;11(4):563-581.

17. Accioli-De-Vaconcellos ZA, Kassar-Duchossoy L, Mira JC. Long term evaluation of experimental median nerve repair by frozen and fresh nerve autografts, allografts and allografts repopulated by autologous Schwann cells. Restor Neurol Neurosci. 1999;15(1):17-24.

18. Rinker BD, Ingari JV, Greenberg JA, et al. Outcomes of short-gap sensory nerve injuries reconstructed with processed nerve allografts from a multicenter registry study. $J$ Reconstr Microsurg. 2015;31(5):384-390.

19. Brooks DN, Weber RV, Chao JD, et al. Processed nerve allografts for peripheral nerve reconstruction: a multicenter study of utilization and outcomes in sensory, mixed, and motor nerve reconstructions. Microsurgery. 2012;32(1):1-14.

20. Cho MS, Rinker BD, Weber RV, et al. Functional outcome following nerve repair in the upper extremity using processed nerve allograft. J Hand Surg Am. 2012;37(11):2340-2349.

21. Elkwood AI, Holland NR, Arbes SM, et al. Nerve allograft transplantation for functional restoration of the upper extremity: case series. J Spinal Cord Med. 2011;34(2):241-247.

22. Squintani G, Bonetti B, Paolin A, et al. Nerve regeneration across cryopreserved allografts from cadaveric donors: a novel approach for peripheral nerve reconstruction. J Neurosurg. 2013;119(4):907-913.

23. Yan Y, Wood MD, Hunter DA, et al. The effect of short nerve grafts in series on axonal regeneration across isografts or acellular nerve allografts. J Hand Surg Am. 2016;41(6):e113e121.

24. Benoit RM, Cohen JK. The relationship between quality and costs: factors that affect the hospital costs of radical prostatectomy. Prostate Cancer Prostatic Dis. 2001;4(4):213-216.

25. Bower WF, Jin L, Underwood MJ, et al. Peri-operative blood transfusion increases length of hospital stay and number of postoperative complications in non-cardiac surgical patients. Hong Kong Med J. 2010;16(2):116-120.

26. Medical Research Council: Memorandum No. 45 (superseding War Memorandum No. 7). Aids to the examination of the peripheral nervous system. 1976. Accessed April 23, 2020. https://mrc.ukri.org/documents/pdf/aids-to-the-examinationof-the-peripheral-nervous-system-mrc-memorandum-no45-superseding-war-memorandum-no-7/ 


\section{Disclosures}

Dr. Adelson received clinical or research support for the study described (includes equipment or material) from AxoGen.

\section{Author Contributions}

Conception and design: Adelson. Acquisition of data: Adelson, Hamant, Brown. Analysis and interpretation of data: Adelson, Kang, Arango. Drafting the article: Hamant. Critically revising the article: all authors. Reviewed submitted version of manuscript: Adelson. Approved the final version of the manuscript on behalf of all authors: Adelson. Statistical analysis: Kang, Arango. Administrative/technical/material support: Adelson, Hamant, Brown. Study supervision: Adelson.

\section{Supplemental Information}

\section{Previous Presentations}

This manuscript was presented at the 48th Annual Meeting of the Section on Pediatric Neurological Surgery of the AANS/CNS, Phoenix, Arizona, in December 2019.

\section{Correspondence}

P. David Adelson: Barrow Neurological Institute at Phoenix Children's Hospital, Phoenix, AZ.dadelson@phoenixchildrens. com. 